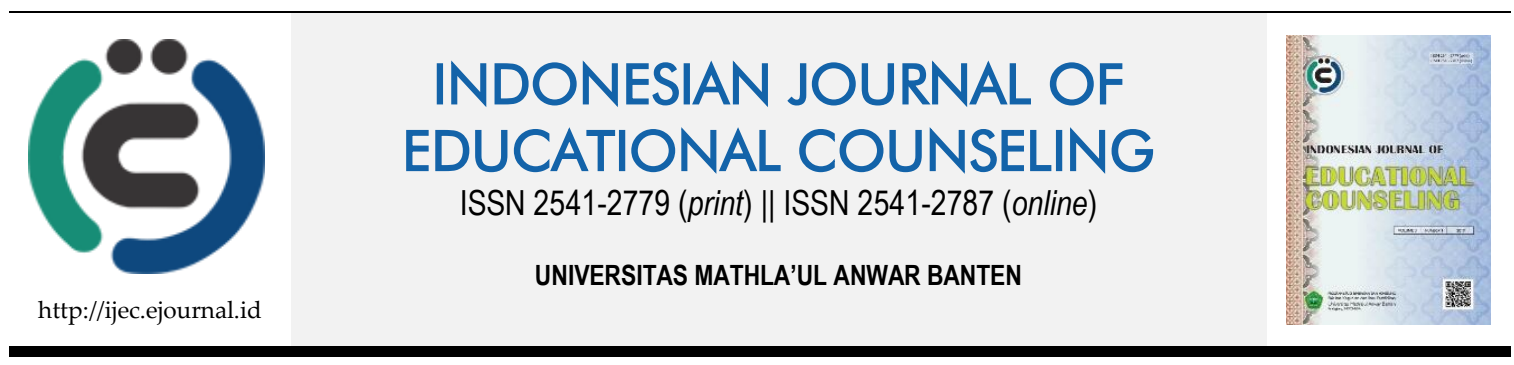

Research Based Article

\title{
Efektivitas Layanan Informasi Karier untuk Meningkatkan Perencanaan Karier Siswa SMA
}

\author{
Silvia Yula Wardani ${ }^{1}$, Rischa Pramudia Trisnani ${ }^{2}$ \\ 1, 2 Universitas PGRI Madiun
}

\begin{tabular}{|c|c|}
\hline Article History & ABSTRACT \\
\hline $\begin{array}{l}\text { Received: } 05.10 .2018 \\
\text { Received in revised form: } \\
20.12 .2018 \\
\text { Accepted: } 10.01 .2019 \\
\text { Available online: } 25.01 .2019\end{array}$ & $\begin{array}{l}\text { High School Education aims to prepare students who will continue their } \\
\text { education to a higher level, while preparing students who will work } \\
\text { immediately if they have completed their education in high school. Experiencee } \\
\text { in the field shows that there are still many students who are confused about } \\
\text { choosing the department (study program) to be entered, especially for high } \\
\text { school students. The purpose of this study was to determine the effectiveness } \\
\text { of information services to improve career planning for students of SMA Negeri } \\
1 \text { Nglames. The sampling technique used was purposive sampling. This } \\
\text { research was conducted at SMA Negeri } 1 \text { Nglames with pre-experimental } \\
\text { design research design. Data collection techniques use a psychological scale } \\
\text { that is the scale of career planning. Data analysis techniques using t-test. The } \\
\text { results showed effective information services to improve career planning } \\
\text { proved after a hypothetical test with the t-test analysis technique of the value } \\
\text { of asympsig (2-tailed)/asympiotic significance } 0.000 \text {, it can be concluded that } \\
\text { information services to improve career planning of students of SMA Negeri } 1 \\
\text { Nglames Kabupaten Madiun. }\end{array}$ \\
\hline & Keywords: Information of Career, Planing Career. \\
\hline
\end{tabular}

DOI: $10.30653 / 001.201931 .55$

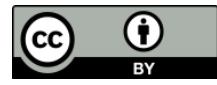

This is an open access article distributed under the terms of the Creative Commons Attribution 4.0 International License, which permits unrestricted use, distribution, and reproduction in any medium, provided the original work is properly cited. ๑ 2019 Silvia Yula Wardani, Rischa Pramudia Trisnani.

\section{PENDAHULUAN}

Peserta didik pada usia remaja akhir adalah sebagai individu yang sedang berkembang mencapai taraf perkembangan secara optimal dalam berbagai aspek kehidupan. Kognitif pada usia remaja masuk pada tahap proses berpikir formal (Piaget, 1971; Santrock, 2003, p. 105), sehingga remaja sudah dapat berpikir secara abstrak dan logis untuk membuat rencana karier.

Remaja memiliki tugas perkembangan, salah satunya adalah mempersiapkan masa depan terutama mempersiapkan kariernya (Havighurst, 1952; Dillard, 1985; Hurlock, 2001). Setiap tahapan perkembangan manusia mempunyai karakteristik yang khas dan

${ }^{1}$ Corresponding author's address: Program Studi Bimbingan dan Konseling, Fakultas Ilmu Pendidikan, Universitas PGRI Madiun. Jl. Setiabudi No.85, Kanigoro, Kartoharjo, Kota Madiun, Jawa Timur 63118. Email: silviawardani@unipma.ac.id 
tugas-tugas perkembangan tersendiri yang bermanfaat sebagai petunjuk arah perkembangan yang normal. Tugas-tugas perkembangan tersebut juga sangat berhubungan dengan pendidikan yang diterima oleh individu. Pendidikan menentukan tugas apakah yang dapat dilaksanakan seseorang pada masa-masa tertentu. Konsep diri dan harga diri akan turun bila seseorang tidak melaksanakan tugas perkembangannya dengan baik, karena individu tersebut akan mendapat celaan dari masyarakat sekitarnya sehingga menimbulkan ketidakbahagiaan bagi individu yang bersangkutan. Sebaliknya, menurut Monks (1992) keberhasilan dalam melaksanakan tugas-tugas perkembangan memberikan perasaan berhasil dan perasaan bahagia.

Perencanaan karier merupakan salah satu aspek yang paling penting dalam perkembangan karier individu (Shertzer \& Stone, 1980). Kecakapan dalam mengambil keputusan merupakan tujuan utama dalam perencanaan karier yang harus ditempuh oleh setiap individu. Sedangkan keputusan yang diambil oleh seseorang mengenai aspekaspek yang akan ditempuh itu tidak terlepas dari pertimbangan terhadap berbagai faktor yang ada dalam tatanan kehidupan masyarakat yang merupakan suatu nilai dan tempat tersedianya berbagai hal yang dapat dimanfaatkan oleh individu bagi pengembangan dirinya. Perencanaan karier yang matang saat sekolah bisa membantu seseorang untuk lebih mengenal dan memahami bakat dan minat yang dimiliki.Kemampuan merencanakan karier perlu dimiliki oleh setiap individu. termasuk siswa di sekolah. Perencanaan karier yang dimiliki oleh siswa berguna untuk pemilihan jenis studi lanjut, dan pemilihan rencana pekerjaan.

Permasalahan di sekolah banyak terjadi siswa masih bingung dalam menentukan studi lanjutnya, kebanyakan memilih studi lanjut karena mengikuti teman dekatnya tanpa pertimbangan bakat, minat dan potensi yang dimilikinya. Keadaan memilih studi lanjut yang asal-asalan ini juga akan berakibat yang kurang positif pada siswa misalkan berkali-kali mengikuti tes masuk perguruan tinggi tetapi sering gagal sehingga harus mengulang berkali-kali.

Hasil penelitian Amin Budiamin (2012) melaporkan bahwa; 90\% siswa SMA di Kabupaten Bandung menyatakan bingung dalam memilih karier untuk masa depan. Pada kenyataan, siswa SMA juga belum bisa mencapai tugas perkembangan karier. Siswa SMA masih ragu dan tidak memiliki kesiapan membuat keputusan karier yang tepat bagi masa depan. Fakta ini menyatakan bahwa banyak remaja mengalami kebimbangan, ketidaksiapan dan stres dalam pembuatan keputusan karier.

Untuk mengatasi masalah perencanaan karier siswa yang masih rendah ini dapat diatasi dengan layanan bimbingan dan konseling khususnya pada bidang karier. Layanan bimbingan dan konseling terdiri dari berbagai layanan salah satunya adalah layanan informasi karier. Layanan informasi marupakan salah satu jenis layanan dalam bimbingan konseling di sekolah yang amat penting untuk membantu peserta didik agar dapat terhindar dari berbagai masalah yang dapat mengganggu terhadap pencapaian perkembangan siswa.

Layanan informasi merupakan layanan yang memungkinan peserta didik menerima dan memahami berbagai informasi (seperti; informasi belajar, pergaulan, karier, pendidikan lanjutan). Tujuan layanan informasi adalah membantu peserta didik agar dapat mengambil keputusan secara tepat tentang sesuatu, dalam bidang pribadi, sosial, belajar maupun karier berdasarkan informasi yang diperolehnya yang memadai (Amti \& Prayitno, 2004; Hastuti \& Winkel, 2004). Informasi pekerjaan (occupational information) adalah data tentang pelatihan dan program pendidikan terkait dengan karier, pola karier 
dan kecenderungan serta peluang bagi pekerjaan itu (Gibson \& Marianne, 2011, p. 446). Melalui layanan informasi diharapkan para peserta didik dapat menerima dan memahami berbagai informasi, yang dapat dipergunakan sebagai bahan pertimbangan dalam pengambilan keputusan untuk kepentingan siswa itu sendiri.

\section{METODE}

Penelitian ini dilaksanakan di SMA Negeri 1 Nglames yang beralamat Jalan Raya Tiron Desa Gunungsari Kecematan Madiun Kabupaten Madiun. Penelitian ini menggunakan pendekatan kuantitatif karena menekankan fenomena-fenomena yang objektif dan dikaji secara kuantitatif. Untuk memaksimalkan objektifitasnya dengan menggunakan angkaangka dan pengelohan statistik. Desain penelitian yang digunakan dalam penelitian ini adalah penelitian eksperimen. Desain eksperimen yang dipakai adalah pre experimental design. Dalam desain eksperimen ini hanya terdapat 1 kelompok, tidak terdapat kelompok kontrol. Desain penelitian ini menggunakan One Group Pretest-Posttest Design. Dipilihnya jenis penelitian ini dikarenakan peneliti dapat melihat hasil dengan lebih akurat, yaitu dengan membandingkan keadaan sebelum diberi perlakuan dan sesudah diberi perlakuan (Sugiyono, 2013). Adapun bagan dari One Group pretest-postest yakni:

$$
\mathrm{O}_{1}=\text { Pretest } \mathrm{X}=\text { Perlakuan } \mathrm{O}_{2}=\text { Postest }
$$

Populasi dalam penelitian ini adalah siswa kelas XII yang berjumlah 306 siswa. Teknik pengambilan sampel yang akan digunakan adalah porpusive random sampling, berdasarkan tujuan penelitian yaitu siswa yang memiliki pemahaman karier rendah berjumlah 34 siswa akan dijadikan subjek penelitian atau sampel penelitian. Menurut Sugiono $(2011,147)$ instrument penelitian adalah "suatu alat yang digunakan untuk mengukur fenomena alam maupun sosial yang diamati". Teknik pengumpulan data yang digunakan dalam penelitian ini adalah skala psikologis. Skala psikologis dalam penelitian ini berbentuk skala sikap dimana hanya mengukur sikap, maka instrumen penelitian akan lebih menekankan pada pengukuran sikap yaitu perencanaan karier siswa. Skala pengukuran perencanaan karier yang digunakan pada penelitian ini adalah adalah skala Likert, yaitu skala yang digunakan untuk mengukur sikap, pendapat, persepsi seseorang atau sekelompok tentang kejadian atau gejala sosial. Analisis data kuantitatif ini untuk menguji keefektifan layanan informasi karier dalam meningkatkan perencanaan karier siswa, maka teknik analisis data dalam penelitian ini meggunakan $T$ test dikarenakan sebaran data yang terkumpul setelah dilakukan uji normalitas hasilnya normal.

\section{HASIL DAN PEMBAHASAN}

Perencanaan karier siswa sangat penting dimiliki oleh siswa SMA terutama kelas XII. Hasil angket perencanaan karier siswa SMA Negeri 1 Nglames Kabupaten Madiun sebelum diterapkan layanan layanan informasi karier menunjukkan sebagian besar berada pada kriteria sangat rendah. Diketahui dari hasil Pretest yang telah dilakukan ada dua puluh tiga siswa termasuk dalam kategori sangat rendah dengan skor 34 s.d. 54,4 dan sebelas siswa dalam kategori rendah dengan skor 54,5 s.d. 74,8. Secara keseluruhan skor rata-rata perencanaan karier siswa sebelum diterapkan layanan informasi karier termasuk dalam kategori sangat rendah. 
Tabel 1. Skor Perencanaan Karier Sebelum Dilaksanakan Layanan Informasi Karier

\begin{tabular}{|c|c|c|c|c|}
\hline Variable & Sub variable & Indikator & Rerata & Kategori \\
\hline \multirow{8}{*}{$\begin{array}{l}\text { Perencanaan } \\
\text { karier }\end{array}$} & \multirow[t]{3}{*}{ Memahami diri } & Mengetahui potensi diri & 55 & Rendah \\
\hline & & Percaya diri & 57 & Rendah \\
\hline & & Berpikir positif & 52 & sangat rendah \\
\hline & \multirow[t]{2}{*}{$\begin{array}{l}\text { Memiliki pengetahuan } \\
\text { studi lanjut }\end{array}$} & $\begin{array}{l}\text { Mengetahui macam-macam } \\
\text { jurusan dalam perguruan } \\
\text { tinggi }\end{array}$ & 55 & Rendah \\
\hline & & $\begin{array}{l}\text { Mengetahui cara memperoleh } \\
\text { program pengembangan }\end{array}$ & 55 & Rendah \\
\hline & \multirow{3}{*}{$\begin{array}{l}\text { Mengetahui jurusan } \\
\text { yang sesuai dengan } \\
\text { kemampuan dirinya }\end{array}$} & Mampu memilih studi lanjut & 52 & sangat rendah \\
\hline & & $\begin{array}{l}\text { Mengetahui tugas, sarana } \\
\text { dan persyaratan dari jurusan } \\
\text { yang diinginkan }\end{array}$ & 52 & sangat rendah \\
\hline & & $\begin{array}{l}\text { Mengetahui peluang dari } \\
\text { jurusan yang diinginkan }\end{array}$ & 52 & sangat rendah \\
\hline Rata-rata & & & 54 & sangat rendah \\
\hline
\end{tabular}

Berdasarkan Tabel 1, nilai rata-rata perencanaan karier siswa semua indikator masuk dalam kategori sangat rendah. Pada indikator mengetahui potensi diri nilai rata-rata 55, sedangkan pada indikator percaya diri nilai rata-rata 57 , pada indikator berpikir positif nilai rata-rata 52, indikator mengetahui macam jurusan di perguruan tinggi nilai rata-rata 55, indikator mengetahui cara memperoleh program pengembangan nilai rata-rata 55, indikator memilih studi lanjut dengan nilai rata-rata 52, indikator mengetahui tugas, sarana dan persyaratan dari jurusan yang diinginkan dengan nilai rata-rata 52 dan pada indikator mengetahui peluang dari jurusan yang diinginkan dengan nilai rata-rata 52, sedangkan skor rata-rata perencanaan karier secara keseluruhan 54 dan termasuk kategori sangat rendah.

Tabel 2. Tingkat Perencanaan Karier Siswa Sebelum Diterapkan layanan Informasi Karier

\begin{tabular}{cccc}
\hline Interval & Kategori & Jumlah & Prosentase \\
\hline $115,7-136$ & sangat tinggi & 0 & 0 \\
\hline $95,3-115,6$ & tinggi & 0 & 0 \\
\hline $74,9-95,2$ & sedang & 0 & 0 \\
\hline $54,5-74,8$ & rendah & 11 & 32,4 \\
\hline $34-54,4$ & sangat rendah & 23 & 67,6 \\
\hline
\end{tabular}

Berdasarkan hasil pretest tersebut peneliti tergugah untuk memberikan sebuah intervensi agar perencanaan karier siswa dapat meningkat, yaitu dengan layanan informasi karier. Dari hasil intervensi diperoleh hasil (posttest) yang dapat dilaporkan pada Tabel 3 dan Tabel 4.

Berdasarkan Tabel 3 dan Tabel 4, nilai rata-rata perencanaan karier siswa semua indikator masuk dalam kategori sedang. Pada indikator mengetahui potensi diri nilai rata-rata 93, sedangkan pada indikator percaya diri nilai rata-rata 90, pada indikator berpikir positif nilai rata-rata 90, indikator mengetahui macam jurusan di perguruan tinggi nilai rata-rata 90, indikator mengetahui cara memperoleh program pengembangan nilai rata-rata 90, indikator memilih studi lanjut dengan nilai rata-rata 89, indikator mengetahui tugas, sarana dan persyaratan dari jurusan yang diinginkan dengan nilai rata- 
rata 89 dan pada indikator mengetahui peluang dari jurusan yang diinginkan dengan nilai rata-rata 85 , sedangkan skor rata-rata perencanaan karier secara keseluruhan 89 dan termasuk kategori sedang.

Tabel 3. Skor Perencanaan Karier Setelah Dilaksanakan Layanan Informasi Karier

\begin{tabular}{|c|c|c|c|c|}
\hline Variable & Sub variable & Indikator & Rerata & Kategori \\
\hline \multirow{8}{*}{$\begin{array}{l}\text { Perencanaan } \\
\text { karier }\end{array}$} & \multirow[t]{3}{*}{ Memahami diri } & Mengetahui potensi diri & 93 & sedang \\
\hline & & Percaya diri & 90 & sedang \\
\hline & & Berpikir positif & 90 & Sedang \\
\hline & \multirow[t]{2}{*}{$\begin{array}{l}\text { Memiliki pengetahuan } \\
\text { studi lanjut }\end{array}$} & $\begin{array}{l}\text { Mengetahui macam-macam jurusan } \\
\text { dalam perguruan tinggi }\end{array}$ & 90 & Sedang \\
\hline & & $\begin{array}{l}\text { Mengetahui cara memperoleh } \\
\text { program pengembangan }\end{array}$ & 90 & Sedang \\
\hline & \multirow{3}{*}{$\begin{array}{l}\text { Mengetahui jurusan } \\
\text { yang sesuai dengan } \\
\text { kemampuan dirinya }\end{array}$} & Mampu memilih studi lanjut & 89 & Sedang \\
\hline & & $\begin{array}{l}\text { Mengetahui tugas, sarana dan } \\
\text { persyaratan dari jurusan yang } \\
\text { diinginkan }\end{array}$ & 89 & Sedang \\
\hline & & $\begin{array}{l}\text { Mengetahui peluang dari jurusan } \\
\text { yang diinginkan }\end{array}$ & 85 & Sedang \\
\hline Rata-rata & & & 89 & sedang \\
\hline
\end{tabular}

Tabel 4. Tingkat Perencanaan Karier Siswa Setelah Diterapkan layanan Informasi Karier

\begin{tabular}{llrr}
\hline Interval & Kategori & Jumlah & Prosentase \\
\hline $115,7-136$ & sangat tinggi & 0 & 0 \\
\hline $95,3-115,6$ & Tinggi & 2 & 5,88 \\
\hline $74,9-95,2$ & sedang & 30 & 88,24 \\
\hline $54,5-74,8$ & rendah & 2 & 5,88 \\
\hline $34-54,4$ & sangat rendah & 0 & 0
\end{tabular}

Berdasarkan hasil analisis menunjukkan terjadinya perubahan pada kondisi awal perencanaan karier siswa, ditandai dengan adanya peningkatan skor skala perencanaan karier siswa baik pada skor total maupun skor setiap indikator. Adapun peningkatan perencanaan karier siswa antara kondisi awal dan kondisi akhir dapat dilihat pada tabel berikut:

Tabel 5. Perubahan Perencanaan Karier Siswa antara Pretest dan Posttest

\begin{tabular}{cccc}
\hline \multirow{2}{*}{ Indikator } & Pretest & Posttest & Perubahan \\
\cline { 2 - 4 } & Skor & Skor & Skor \\
\hline 1 & 55 & 93 & 38 \\
\hline 2 & 57 & 90 & 33 \\
\hline 3 & 52 & 90 & 38 \\
\hline 4 & 55 & 90 & 35 \\
\hline 5 & 55 & 90 & 35 \\
\hline 6 & 52 & 89 & 37 \\
\hline 7 & 52 & 89 & 37 \\
\hline 8 & 53 & 85 & 32 \\
\hline Rata-rata & 54 & 89 & 35 \\
\hline
\end{tabular}


Terjadi peningkatan komunikasi interpersonal siswa antara sebelum dan sesudah diberikan layanan informasi karier. Rata-rata perubahan yang terjadi adalah sebesar 35 dari data pretest sebesar 54 menjadi 89. Rata-rata setiap aspek tingkat perencanaan karier siswa sebelum diberi layanan berada pada kategori sangat rendah, setelah diberikan layanan informasi karier terjadi peningkatan menjadi kategori sedang. Ini berarti bahwa layanan informasi karier efektif untuk meningkatkan perencanaan karier siswa SMA Negeri 1 Nglames Kabupaten Madiun. Agar lebih mudah dalam melihat perubahan kondisi awal dan kondisi akhir tingkat perencanaan karier siswa dapat dilihat pada Gambar 1.

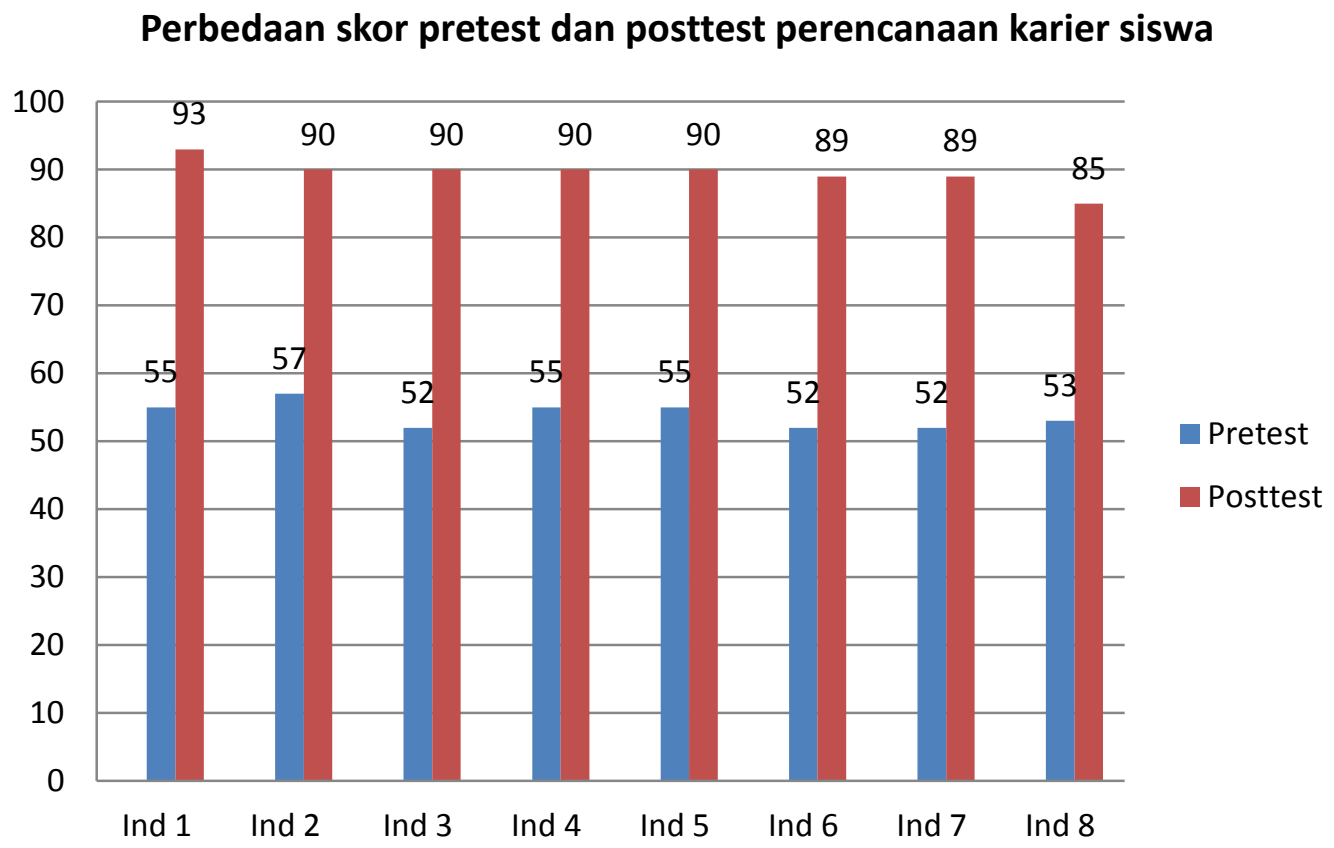

Gambar 1. Grafik perbedaan skor pretest dan posttest pada masing-masing indikator

Untuk menguji keefektifan layanan informasi karier dilakukan dengan teknik statistik parametris, yaitu menggunakan Uji T atau $T$ test menggunakan program SPSS. $T$ tes digunakan untuk menguji signifikasi hipotesis komparatif 2 sampel yang berkorelasi bila datanya berbentuk ordinal dan atau berjenjang (Sugiyono, 2013: 137). Hasil perhitungan melalui SPSS sebagai berikut :

\section{Paired Samples Correlations}

\begin{tabular}{|l|l|r|r|}
\hline & \multicolumn{1}{|c|}{$\mathrm{N}$} & Correlation & \multicolumn{1}{c|}{ Sig. } \\
\hline Pair 1 Pretest \& Posttest & 34 & .480 & .004 \\
\hline
\end{tabular}

Gambar 2. Hasil analisis paired samples corelations

Gambar 2 menunjukkan hasil analisis paired samples corelations nilai Sig sebesar 0,04 disini memiliki arti ada hubungan antara hasil pretest dan posttest karena jika dibandingkan nilai sig $<0,05$ atau $0,04<0,05$. 


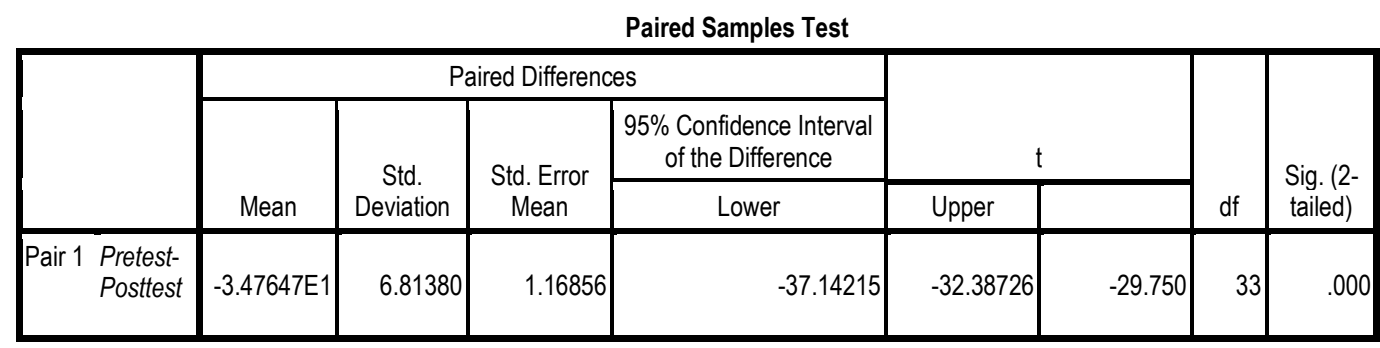

Gambar 3. Hasil paired samples test

Berdasarkan hasil gambar 3 tentang paired samples test menunjukkan nilai sig (2tailed sebesar 0,000 yang mana $<0.05$ maka dapat disimpulkan terdapat perbedaan antara nila pretest dan posttest atau dapat disimpulkan layanan informasi karier efektif untuk meningkatkan perencanaan karier siswa SMA Negeri 1 Nglames Kabupaten Madiun.

\section{SIMPULAN}

Berdasarkan hasil analisis data yang telah dilakukan dengan menggunakan teknik analisis $T$ test dapat disimpulkan terdapat hubungan antara hasil pretest dan posttest, selain itu terdapat perbedaan antara hasil pretest dan posttest sehingga dapat disimpulkan layanan informasi karier efektif untuk meningkatkan perencanaan karier siswa SMA Negeri 1 Nglames Kabupaten Madiun.

\section{REFERENSI}

Amti, E., \& Prayitno. (2004). Layanan bimbingan dan konseling kelompok. Padang: Jurusan Bimbingan dan Konseling Fakultas Ilmu Pendidikan Universitas Negeri Padang.

Budiamin, A. (2002). Manajemen layanan bimbingan karir pada SMU negeri di Kabupaten Bandung. Psikopedagogia, Jurnal Psikolog Pendidikan dan Bimbingan, 2(2), 259-266.

Dillard, J. M. (1985). Life long career planning.Columbus, Ohio: Bell \& Howell Company.

Esterberg, K. G. (2002). Qualitative methods in social research. New York: Mc Graw Hill.

Gibson, L, R., \& Marianne, M. H. (2011). Bimbingan dan konseling. Yogyakarta: Pustaka Belajar.

Hastuti, W. S., \& Winkel, W. S. (2004). Bimbingan dan konseling di institusi pendidikan. Yogyakarta: Media Abadi.

Havighurst R. J. (1952). Developmental tasks and education. New York: David McKay.

Hurlock, E. B. (2001). Developmental psychology. New York: Tata McGraw-Hill Education.

Monks, F. J. (1992). Development of gifted children: The issue of identification and programming. In F. J. Mönks \& W. Peters (Eds.), Talent for the future (pp. 191-202). Assen: Van Gorcum. 
Piaget, J. (1971). The theory of stages in cognitive development. In D. R. Green, M. P. Ford, \& G. B. Flamer (Eds.), Measurement and Piaget (pp. 1-111). New York: McGraw-Hill.

Prayitno. (2004). Layanan bimbingan dan konseling. Padang: Universitas Negeri.

Santrock, J. W. (2003). Adolescence (Perkembangan remaja). Jakarta: Erlangga.

Shertzer, B. E., \& Stone, S. C. (1980). Fundamentals of counseling. Boston: Houghton Mifflin Harcourt (HMH).

Sugiyono. (2011). Metode penelitian kuantitatif kualitatif dan RED. Bandung: Alfabeta. 